\title{
CONTRIBUIÇÕES DO PLURILINGUISMO \\ PARA O APRENDIZADO DO \\ PORTUGUÊS BRASILEIRO COMO \\ LÍNGUA DE ACOLHIMENTO EM \\ CONTEXTO MIGRATÓRIO
}

Teurra Fernandes Vailatti ${ }^{1}$

\begin{abstract}
Resumo: Apresentamos o relato da experiência realizada no Projeto de Extensão Português Brasileiro para Migração Humanitária, da Universidade Federal do Paraná, que oferece cursos de português brasileiro $(\mathrm{PB})$ à população migrante. A pesquisa analisa onze produções escritas de alunos de nível básico, de maioria haitiana e síria, realizadas no $2^{\circ}$ semestre de 2018. A partir de uma análise discursiva das produções, fundamentada na teoria do Círculo de Bakhtin (Bakhtin, 1992, 1998; Bakhtin; Voloshinov, 2009), verificamos como os alunos usaram aferramenta língua portuguesa para construir uma enunciação particular, com a consciência de falar sobre si, em um movimento de reafirmação identitária e de superação dos silenciamentos que a migração impôs. Na discussão, afinando as relações entre o conceito de língua de acolhimento e plurilinguismo, refletimos como a noção de competência plurilíngue e pluricultural favoreceu a relação aprendiz-língua.
\end{abstract}

Palavras-chave: Língua de acolhimento, plurilinguismo, populações migrantes, discurso, identidade.

\section{CONTRIBUTIONS OF PLURILINGUALISM TO THE LEARNING OF BRAZILIAN PORTUGUESE AS A HOST LANGUAGEIN MIGRATORY CONTEXT}

\begin{abstract}
We present a report of the experience carried out at the Projeto de Extensão Português Brasileiro para Migração Humanitária, of Universidade Federal do Paraná, which offers Brazilian Portuguese (BP) courses to the migrant population. The research analyzes eleven written productions of basic-level students, mostly Haitian and Syrian, written in the second semester of 2018. From a discursive analysis of the productions, based on Bakhtin's Circle theory (Bakhtin, 1992, 1998; Bakhtin; Voloshinov, 2009), we established how the students used the Portuguese language tool to build a particular enunciation, whilekeeping in mind that they were talking about themselves, reassuring their identity and overcoming the silences imposed by the migration context. In our discussion, by refining the relation between the concept of host language and plurilingualism, we contemplated how the notion of plurilingual and pluricultural competence enhanced the learner-language relation.
\end{abstract}

Keywords: Host language. Multilingualism. Migrant population. Discourse. Identity.

1 Mestra em Educação, Universidade Federal do Paraná (UFPR), e-mail: teurravailatti@hotmail.com, link para o Lattes: http://lattes.cnpq.br/4264823488365942. 


\section{Introdução}

Este artigo apresenta os resultados parciais de uma pesquisa2 situada no contexto do Projeto de Extensão Português Brasileiro para Migração Humanitária (PBMIH), desenvolvido no curso de Letras e vinculado ao Programa de Extensão Política Migratória e Universidade Brasileira (PMUB) da Universidade Federal do Paraná (UFPR). Pautado no conceito de língua de acolhimento,o PBMIHoferece cursos gratuitos de português brasileiro (PB), com o objetivo promover a superação das barreiras linguísticas das populações migrantes residentes na cidade de Curitiba e em sua região periférica, no Estado do Paraná.

O conceito de língua de acolhimento diz respeito ao migrante e refugiado que tem uma urgente necessidade de domínio da língua nacional para garantir sua sobrevivência no país. Nossa argumentação retoma o conceito, questionando em que medida o Português Brasileiro - PB seria, de fato, uma língua de acolhimento. Nessa perspectiva, relembramos que o cenário migratório diz respeito não só à relação do migrante com a língua nacional, mas também abarca suas relações com as demais línguas (maternas, estrangeiras, aprendidas, etc.) e culturas que compõem o seu contexto sociocomunicativo.

Desse modo, reconhecendo a natureza plurilíngue do repertório linguístico dos alunos migrantes, buscamos integrara didática da intercompreensão (IC), como abordagem pertencente ao plurilinguismo, e analisar como sua inserção pedagógica nos projetos de Português como Língua de Acolhimento (PLAc), mais especificamente no PBMIH, pode contribuir para

2 Pesquisa realizada na disciplina Prática de Pesquisa em Educação II, do curso de Licenciatura em Letras Português da UFPR, sob a orientação da Profa. Dra. Karine Marielly Rocha da Cunha e com a colaboração do Prof. Dr. Francisco Javier Calvo de Olmo. o ensino-aprendizado da língua nacional e o efetivo acolhimento destas populações.

Além de entrar em contato com a realidade educacional do projeto e de ter uma visão global de sua estrutura e de suas dinâmicas de ensinoaprendizado, na pesquisa empírica, uma unidade temática foi elaborada e aplicada em uma turma de nível básico (Básico 1A), formada por um grupo de aproximadamente quinze alunos, de maioria haitiana e síria. verificamos como a IC atuou enquanto ferramenta didática no contexto do PBMIH, ampliando os recursos pedagógicos para o aprendizado do PB e beneficiando a relação aprendiz-língua. Através de uma análise discursiva das produções escritas, percebemos como os alunos usaram a língua em função de suas necessidades, vontades individuais e motivações internas em um movimento de reafirmação da própria identidade e de superação dos silenciamentos que a situação de mudança de país impôs.

Apesar dos inegáveis avanços na área, o ensino-aprendizado de PLAc é um tema recente, que ainda carece de investigação. Nesse sentido, considerando o desafio que é a estruturação de cursos para que migrantes e refugiados possam desenvolver suas competências em comunicação na língua nacional, esta pesquisa pretendeu então reconhecer o plurilinguismo inerente ao contexto migratório e analisar sua inserção pedagógica no PBMIH, de modo a trazer contribuições teóricas e metodológicas para o campo de estudos no qual está situada.

\section{Que língua de acolhimento?}

O crescente fluxo migratório que desloca populações inteiras de seus lugares de origem, tem mobilizado a atenção dos governos, da mídia, das organizações não governamentais e de diversos setores da sociedade, devido aos impactos e transformações sociais que provoca. 
Neste contexto, o Brasil se situa como país de acolhimento de migrantes refugiados que vêm em busca de liberdade e proteção ante uma situação adversa (perseguição, conflito, violação de direitos, catástrofes naturais, etc). Atualmente, o país recebe pessoas de diversas nacionalidades, dentre elas, haitiana, venezuelana, síria, libanesa e congolesa.

O visto humanitário, em sua legislação, garante a estas pessoas o direito de acesso ao trabalho, à educação, à saúde, à moradia, etc. Contudo, não há ações governamentais que sejam eficazes para a efetiva inserção destas populações na sociedade brasileira. Resulta que são iniciativas da sociedade civil-de instituições não governamentais, de organizações religiosas, do meio acadêmico e do setor privado - que acabam oferecendo suporte para o acolhimento dos refugiados.

Neste cenário, projetos de extensão desenvolvidos em universidades públicas e privadas do país oferecem cursos gratuitos de português brasileiro (PB) para que migrantes refugiados possam aprender formalmente a língua nacional, já que seu domínio é essencial para a manutenção da vida social como um todo. Apesar da carência de políticas governamentais de acolhimento linguístico, estes projetos vêm amadurecendo e ganhando visibilidade, consolidando uma nova área no ensino-aprendizado de línguas - a do Português como Língua de Acolhimento (PLAc).

Como exemplos citamos o Projeto Português Brasileiro para Migração Humanitária, da Universidade Federal do Paraná (PBMIH/ UFPR), o Projeto Português para Falantes de Outras Línguas, da Universidade Tecnológica Federal do Paraná (PFOL/UTFPR), o Projeto Português para Estrangeiros: língua-cultura e acolhimento em contexto de imigração e refúgio, da Universidade de Brasília, (PROACOLHER/ UnB); o Projeto Português para Refugiados no Brasil, sob organização da Cáritas Rio de Janeiro em parceria com a Universidade Estadual do Rio de Janeiro (UERJ); o Programa de Português para Estrangeiros, da Universidade Federal do Rio Grande do Sul (PPE/UFRGS); e o Projeto Refugiados na Paraíba: integração linguística e transculturalidade, da Universidade Federal da Paraíba (UFPB).

Nas últimas décadas, o ensino do Português como Língua Estrangeira (PLE) ganhou contornos em cursos de extensão universitária e em escolas de idiomas para atender a demanda de aprendizado de turistas, de intercambistas e de funcionários de empresas estrangeiras que migraram para o Brasil com suas famílias. Diferentemente deste contexto, hoje, o ensino do PB como língua de acolhimento se destina aos migrantes refugiados recémchegados ao país com necessidades específicas de aprendizado da língua, essencialmente vinculadas ao acesso à cidadania.

O conceito de língua de acolhimento busca então um enquadramento mais adequado que os termos língua estrangeira e segunda língua para designar o ensino-aprendizado da língua nos contextos migratórios atuais. Distintamente dos dois termos anteriores, o conceito diz respeito ao falante em imersão no país de acolhimento, que possui uma urgente necessidade de domínio da língua para a inserção na sociedade; o que traz outro sentido e relevância para o aprendizado: o de sobrevivência no país (GROSSO, 2010).

Dados da pesquisa nacional intitulada Perfil socioeconômico dos refugiados no Brasil: Subsídios para elaboração de polícias ${ }^{3}$, apontam que migrantes refugiados que vêm para o Brasil, têm alto nível de escolarização e uma vida constituída de bens materiais e simbólicos nos países de origem. Ao chegarem aqui, encontram-se em situação

3 A pesquisa Perfil socioeconômico dos refugiados no Brasil: Subsídios para elaboração de políticas apresenta um diagnóstico completo do perfil da população de refugiados no Brasil. Disponível em:<https://www.acnur.org/ portugues/wp-content/uploads/2019/07/Pesquisa-PerfilSocioeconômico-Refugiados-ACNUR.pdf>. Acesso em: 05 jul. 2019. 
de privação destes recursos e, muitas vezes, deparam-se com situações de vulnerabilidade, instabilidade, preconceito e marginalização, que podem ser agravadas pelo não domínio da língua. Por isso, os processos de migração são extremamente desafiadores para estes sujeitos que almejam ressignificar a vida em condições de dignidade. Ao serem submetidos a processos de aculturação e silenciamento, acabam integrando uma categoria abstrata de migrante-refugiado, homogeneizante de suas identidades individuais.

Neste cenário, ainda que o conceito de língua de acolhimento possa trazer uma conotação positiva para o contexto da migração, é preciso problematizar os sentidos que acarreta. A partir do debate teórico-conceitual de Cabete (2010), Grosso (2010) e Anunciação (2017), ressaltamos que a principal preocupação é o equívoco de condicionar o domínio da língua a uma adequação pré-estabelecida e não a uma inserção linguísticosocial organicamente construída. Em outras palavras, como se o pertencimento do migrante à sociedade estivesse estritamente vinculado ao domínio legitimado da língua nacional.

Um exemplo de instrumento que provoca este tipo de adequação no domínio da língua é o Certificado de Proficiência em Lingua Portuguesa para Estrangeiros (Celpe-Bras), certificado brasileiro de proficiência em português como língua estrangeira desenvolvido pelo Ministério da Educação (MEC), reconhecido oficialmente e exigido para requerentes de visto permanente no Brasil. Ora, a emissão de um certificado que condiciona o acesso aos direitos civis pode ser vista como um avanço para as políticas linguísticas, mas de fato agrega uma perspectiva positiva para a inserção do migrante na sociedade?

Uma breve análise do Caderno de resumos do último Simpósio Internacional Celpe-Bras - IV Sincelpe, realizado em 2017, no Centro de Línguas e Interculturalidade da Universidade Federal do Paraná (CELIN-UFPR), mostrou que, com exceção das falas de especialistas na área, ainda há pouco questionamento científico relacionado ao aspecto regulador e homogeneizante desta certificação para o ensino-aprendizado do PB em contexto migratório. As pesquisas atualmente estão mais focadas em abordar aspectos técnicos e operacionais do exame, como critérios de elaboração, parâmetros de avaliação, formação de aplicadores, internacionalização, etc.

Os que se direcionam para um entendimento problemático da questão argumentam que se a identidade é uma prática discursiva socialmente construída, a limitação de espaços de enunciação, ou a regulação destes espaços, tende a submeter as demais línguas e culturas a um projeto homogeneizante e normativo. $\mathrm{Na}$ prática, pressupomos que isto significaria, por exemplo, transformar cursos de $\mathrm{PB}$ para migrantes refugiados em cursos preparatórios para o CelpeBras; significaria determinar o que eles devem aprender e não o que eles precisam aprender, o que eles devem falar e não o que eles querem falar - reforçando assim as desigualdades linguísticas, culturais e identitárias.

Neste cenário, compreendemos que é necessário refletir sobre o conceito de língua de acolhimento em contexto brasileiro e seus reais impactos na promoção do acolhimento ou no reforço da exclusão, nos diferentes espaços sociais pelos quais migrantes e refugiados transitam. Será que a língua de acolhimento para estas populações é de fato o português? Ou será que não seriam as línguas de suas biografias, nesse caso, o Àrabe, o Crioulo Haitiano, o Espanhol, o Francês e o Inglês? Assim, diante da constatação de que, no contexto da migração, o acolhimento não diz respeito apenas à relação do migrante com o PB, com a língua nacional, mas também abarca suas relações com as outras línguas que compõem seu repertório linguístico, sugerimos que o termo línguas 
de acolbimento seria mais apropriado para designar as situações sociocomunicativas que, expressas através destas línguas, perpassam a realidade destes indivíduos.

É nessa perspectiva de questionamento que o plurilinguismo pode atuar, agindo a favor de um movimento de empoderamento identitário, já que ao reconhecer a diversidade e a igualdade das línguas e culturas em um mesmo espaço, se caracteriza como um incentivo para a participação ativa dos migrantes na sociedade. Visando aprofundar o olhar sobre esta questão, é também na defesa de uma perspectiva dialógica de acesso à cidadania que nossa experiência investigativa buscou afinar as relações entre os conceitos de língua de acolhimento e de plurilinguismo.

\section{O plurilinguismo em projetos de Português como Língua de Acolhimento}

Nossa pesquisa se situa no contexto do Projeto de Extensão Português Brasileiro para Migração Humanitária (PBMIH), desenvolvido no curso de Letras e vinculado ao Programa Política Migratória e Universidade Brasileira (PMUB), da Universidade Federal do Paraná (UFPR). Desde 2015, o PBMIH é um dos projetos integrantes deste Programa e tem o objetivo de oferecer cursos gratuitos de PB para a população migrante e refugiada residente na cidade de Curitiba e em sua região periférica, no estado do Paraná.

O PBMIH atende uma média de duzentos alunos por semestre, oferece aulas em diferentes níveis de ensino (letramento, básico, préintermediário, intermediário, entre outros) e conta com a participação de professores bolsistas e voluntários oriundos do curso de Letras da UFPR. Estruturado a partir do conceito de língua de acolhimento, o projeto ainda possui uma estratégia didática específica, chamada porta giratória, que propõe uma outra lógica de progressão de conteúdos de ensino. Assim, ao invés de seguir uma progressão linear (em que um conteúdo fica atrelado ao outro), cada aula possui uma unidade temática independente, com início, meio e fim.

No projeto, as ações pedagógicas, como a estruturação do currículo, a seleção de conteúdos a serem trabalhados, a elaboração de materiais didáticos, a aplicação de aulas, a avaliação de aprendizado do público alvo, entre outras, ficam a cargo dos professores participantes e estão essencialmente voltadas para suprir as necessidades reais de comunicação dos migrantes refugiados. Sendo assim, geralmente são abordadas temáticas vinculadas ao acesso à cidadania, por exemplo: como se comportar em uma entrevista de emprego, como marcar uma consulta médica, como elaborar um currículo, etc.

No entanto, como dissemos anteriormente, para além da necessidade de domínio do PB como língua nacional, há uma outra realidade inerente às dinâmicas sociocomunicativas da população migrante, que diz respeito à naturalidade com que estes falantes transitam entre os universos linguísticos e culturais, nas situações reais de comunicação (presenciais e virtuais) nas quais estão inseridos. Os alunos migrantes, geralmente falantes de Francês, Crioulo Haitiano, Espanhol, Inglês e Árabe, possuem um repertório de grande diversidade linguística e cultural ${ }^{4}$, que pode então ser aproveitado no processo de aprendizado da língua nacional.

Nesse sentido, realizamos um movimento de mudança de paradigma no ensino-aprendizado de línguas, tratando-se do distanciamento das concepções mais tradicionais e nos aproximamos do plurilinguismo, ou seja, nos deslocamos de noções isoladas e estáticas de ensino-aprendizado para uma concepção que justamente valoriza a 4 A pesquisa de Anunciação (2017) constatou a natureza plurilíngue dos repertórios linguísticos individuais dos alunos do PBMIH, da UFPR. 
natureza plurilíngue dos repertórios linguísticos dos alunos migrantes: a didática do plurilinguismo. Presumimos que tal perspectiva pode atuar justamente facilitando o aprendizado do $\mathrm{PB}$, não como uma língua fechada em si mesma, mas, pelo contrário, por considerar o perfil do público alvo, aproveita desta bagagem de línguas faladas, conhecidas, aprendidas anteriormente para investir no aprendizado do português.

$\mathrm{O}$ termo bagagem de línguas é usado aqui também no sentido de se opor à ideia de que o domínio de uma língua encontraria sua mais alta expressão na imagem abstrata e idealizada do falante nativo. Em perspectiva similar a de Zarate et al. (2008), consideramos que todo falante possui seu próprio repertório linguístico, construído na interação socioverbal em contextos reais, únicos e singulares. Tal repertório, inteiro em si, rompe com a noção de que o domínio das línguas em competências parciais deveria ser desconsiderado por ser deficiente para uma competência global de comunicação. Assim, a partir de Escudé e Janin (2010), compreendemos, então, que cada falante possui organicamente em sua biografia linguística competências plurilíngues e pluriculturais, que podem ser aproveitadas para facilitar o aprendizado da nova língua.

Ainda, a inserção da perspectiva plurilíngue e pluricultural em projetos como o PBMIH poderia impactar positivamente nas políticas linguísticas do espaço acadêmico, no movimento de internacionalização das universidades, que integra ações como o reingresso das populações migrantes, a revalidação de diplomas, os convênios bilaterais, a mobilidade acadêmica, etc. Diante da utilização privilegiada da língua nacional e da tentação de imposição de um monolinguismo neste espaço, há o risco de perda de uma autonomia discursiva daqueles migrantes que ali ingressam. Nesse sentido, o plurilinguismo, como via complementar das ações de acolhimento, facilitaria a abertura para uma participação mais democrática destes alunos no ensino superior.

Tais reflexões delinearam o propósito de nossa experiência investigativa conduzida no PBMIH durante o ano de 2018, mais especificamente no segundo semestre. A pesquisa teve como objetivo integrar a intercompreensão (IC), abordagem pertencente plurilinguismo, como recurso didático para beneficiar a relação aprendiz-língua no processo de aprendizado do $\mathrm{PB}$. Na investigação, presumimos que a IC é uma ferramenta pedagógica plausível para a aquisição de conhecimentos nos processos de ensino-aprendizado de línguas.

Assim,nocampoda didáticadoplurilinguismo, compreendemos a IC a partir da definição do Cadre de Référence pourles Approches Plurielles des Langues et dês Cultures (CARAP) ${ }^{5}$. O documento esclarece que as semelhanças estruturais das línguas, sobretudo as de mesma família, permitem estabelecer relações para facilitar a construção dos sentidos. Desse modo, as línguas conhecidas, aprendidas, faladas são universos interdependentes por entre os quais o falante pode transitar para aprimorar sua competência global de comunicação, especialmente na compreensão (CANDELIERet al., 2007).Nessa perspectiva, a IC integraas chamadas Abordagens Plurais e dialoga com seus outros eixos estruturadores - interculturalidade, sensibilização para a diversidade linguística e didática integrada de línguas.

Em complementação, a partir de Escudé e Janin(2010), de PalmerinieFaone (2014), de Andrade e Martins (2015) e de Sheeren (2016),situamos a IC também como um conceito didático quepode ser integrado no ensino-aprendizado do PB para: (1) instaurar um ambiente plurilíngue e pluricultural em sala de aula; (2) presentificar a língua materna

5 O CARAP, do Conselho da Europa, é o quadro de referência que tem o objetivo de promover o desenvolvimento de uma educação plurilíngue e intercultural. O site do CARAP oferece uma série de documentos e materiais didáticos que constituem o instrumental para o propósito do projeto. 
e valorizar o repertório discursivo do aluno como ponto de partida para o aprendizado do PB, promovendo entrecruzamentos dos universos linguísticos-comunicativos; (3) contribuir com uma aproximação afetiva da língua inicialmente imposta devido à situação de refúgio no país; (4) sensibilizar o aluno para as relações linguísticas (fonéticas, morfológicas, lexicais, etc.) e culturais que ele mesmo pode tecer para decifrar, interpretar e assimilar novos conhecimentos, como sujeito ativo no processo de aquisição da língua. (VAILATTT; OLMO, 2018).

Além disso, mesmo que a IC esteja agindo em prol da aquisição de conhecimentos na língua nacional, a configuração heterogênea das classes dos projetos de PLAc, geralmente formadas por alunos de diferentes nacionalidades, engendra situações de interação socioverbal que não descartam a possibilidade de um enriquecimento simultâneo dos repertórios plurilíngues e pluriculturais dos migrantes, superando inclusive o caráter monolíngue dos processos de ensino-aprendizado em tais contextos.

Em complementação, presumimos que a teoria bakhtiniana nos é pertinente, sobretudo a partir do conceito de enunciado e das noções de dialogismo e alteridade, pois demonstra uma aguda percepção da paisagem real das línguas, ou seja, considera a diversidade linguística e cultural das situações reais de comunicação nas quais migrantes e refugiados estão inseridos(BAKHTIN, 1992, 1998; BAKHTIN; VOLOCHINOV, 2009). Assim, em termos de afinidade teórico-conceitual, por considerar a linguagem como discurso integrado à vida sociocultural, produto da interação socioverbal entre os falantes, a teoria pode conversar com a noção plurilingue e pluricultural.

Nesse sentido, também compreendendo os processos de ensino-aprendizado de línguas na perspectiva sociointerativa da comunicação, a partir da teoria bakhtiniana consideramos que o aprendizado do PB, fundamentado na vivência, na realidade de mundo e nas necessidades concretas de comunicação do aluno, deve ser um catalisador de sua experiência discursiva. Assim, ao se posicionar ao lado das competências do aluno, a IC faz ele criar recursos para acionar seus conhecimentos de contexto, de mundo e de ordem extralinguística, para interagir com os discursos, indo da forma aos sentidos, minimizando a opacidade do PB.

Ainda, a perspectiva de ensino-aprendizado de línguas preconizada no Quadro Europeu Comum de Referência para as línguas (QECR) ${ }^{6}$ traz uma noção complementar que possibilita compreender que interagir em uma língua significa articular uma série de competências para gerenciar a comunicação com outro falante. As competências exigidas em situações reais de comunicação são então diversas, complexas e multifacetadas. Para suprir as necessidades concretas da comunicação, o falante deve ser capaz de agir linguisticamente, socialmente, culturalmente, cognitivamente, afetivamente, etc., na vontade de se fazer entender e de entender o outro. Nessa perspectiva, a comunicação verbal também exigiria do falante uma capacidade intercompreensiva, que inclusive tange as dimensões afetivas, cognitivas, culturais, sociais e linguísticas citadas.

Concluindo, além de desestabilizar noções pedagógicas já cristalizadas e conduzir para novos modos ensino-aprendizado da língua, a principal contribuição da didática da IC, inscrita na perspectiva mais ampla do plurilinguismo, é o fato de considerar as línguas e culturas um meio através do qual os alunos podem aprimorar a competência global de comunicação, considerando também a

6 O QECR, do Conselho da Europa, é o documento oficial de referência que se propõe a estabelecer parâmetros comuns para o ensino, aprendizagem e avaliação de línguas estrangeiras nos países europeus. CONSEIL DE L'EUROPE. Cadre européen commun de référence pour les langues :apprendre, enseigner, évaluer -volume complémentaire avec de nouveaux descripteurs. Paris: Les Editions Didier, 2018.Versão em francês. 
interação ativa entre as línguas, entre as culturas e entre as pessoas.

Ainda sobre o plurilinguismo, vale ressaltar que é uma mudança de paradigma que não está necessariamente se opondo às correntes metodológicas anteriores, nem substituindo por completo outras dinâmicas de ensino-aprendizado, inclusive as mais tradicionais; até porque a dinâmica escolar como um todo pode atestar empiricamente que a força do hábito normativista nos modos de ensinar e de aprender línguas não concebe revoluções imediatas. Em contrapartida, por reconhecer a natureza plurilíngue e pluricultural da comunicação socioverbal em contexto migratório, o plurilinguismo não quer senão agregar um novo entendimento, para melhor responder às atuais demandas de um mundo globalizado.

\section{Falar de si em português brasileiro: as vozes dos migrantes e refugiados}

A partir das reflexões anteriores, nossa pesquisa avalia uma unidade temática (UT) independente, elaborada e aplicada no $2^{\circ}$ semestre de 2018, em uma turma de nível básico (Básico 1A) do PBMIH, formada por um grupo de aproximadamente quinze alunos, de maioria haitiana e síria. Na primeira parte da análise, a partir dos referenciais teóricos do conceito didático de IC (PALMERINI; FAONE, 2014; ANDRADE; MARTINS, 2015; SHEEREN, 2016), pontuamos aspectos da interação do grupo de alunos com o material didático para verificar de que modo a IC atuou como recurso facilitador do aprendizado do PB. Nasegunda parte, aqui apresentada, realizamos uma análise discursiva das produções escritas dos alunos, fundamentada na teoria do Círculo de Bakhtin (BAKHTIN, 1992, 1998; BAKHTIN; VOLOSHINOV, 2009), para verificar como os alunos de serviram da ferramenta língua portuguesa (em seus aspectos gramaticais, lexicais, fonológicos, etc.) para falar sobre si - produzindo uma enunciação particular.

Em linhas gerais, na elaboração da UT consideramos o contexto dos alunos, recémchegados ao país, e optamos pela escolhado tema conhecer pessoas. $\mathrm{Na}$ proposta, foram selecionadas seis entrevistas de brasileiros do projeto 7 bilhões de outros, criado pelo jornalista francês Yann ArthusBertrand. Assim, a partir da análise dos conteúdos linguísticos e culturais das entrevistas, os alunos aprenderam as estruturas usadas para se apresentar em PBa partirdas seguintes informações: nome, idade, profissão, cidade/estado/país e estado civil. Desse modo, o objetivo final da sequência didática eraque eles mesmos se apresentassem (oralmente e por escrito), como se fossem entrevistados para o projeto do jornalista francês.

Considerando a sala de aula um lugar que promova a interação socioverbal de modo efetivo, elegemos o gênero entrevista intencionando criar um espaço para que os alunos pudessem falar sobre si, obviamente, recuperando a materialidade linguística dosenunciados estudados para elaborar o próprio discurso individual. Nessa perspectiva, partimos do pressuposto de que as estruturas linguísticas anteriormente estudadas seriam por eles usadas em sua esfera sígnica, ou seja, no sentido particular que adquirem no contexto, como discurso integrado à vida sociocultural (BAKHTIN, 2009).

Em muitos livros didáticos para ensino de Português como Língua Estrangeira (PLE), de nível básico, o tema apresentação pessoal traz atividades de preenchimento de formulários com informações pessoais (nome, idade, nacionalidade, profissão, endereço, etc.), em que a capacidade expressiva do aluno fica limitada a um exercício quase mecânico de manipulação das formas linguísticas.

Dos poucos materiais didáticos publicados de fácil acesso, direcionados especificamente a 
migrantes e refugiados, temos o exemplo da apostila intitulada Pode Entrar: Português do Brasilpara Refugiadas $e$ Refugiados ${ }^{7}$, que parece reproduzir as mesmas dinâmicas que os livros didáticos de PLE estruturam. Na página extraída da apostila (FIGURA 1), é pedido ao aluno que complete o formulário da Polícia Federal, para realização do Registro Nacional de Estrangeiro. Atividades desta natureza, ainda que inseridas na temática do acesso à cidadania, costumam não dar muito espaço para a diversidade e a criatividade linguística, exigindo do aluno maior adequação a um estilo determinado de produção escrita.

Formulários estão em todos os lugares, você sabe preencher seus dados? Coloque seus dados

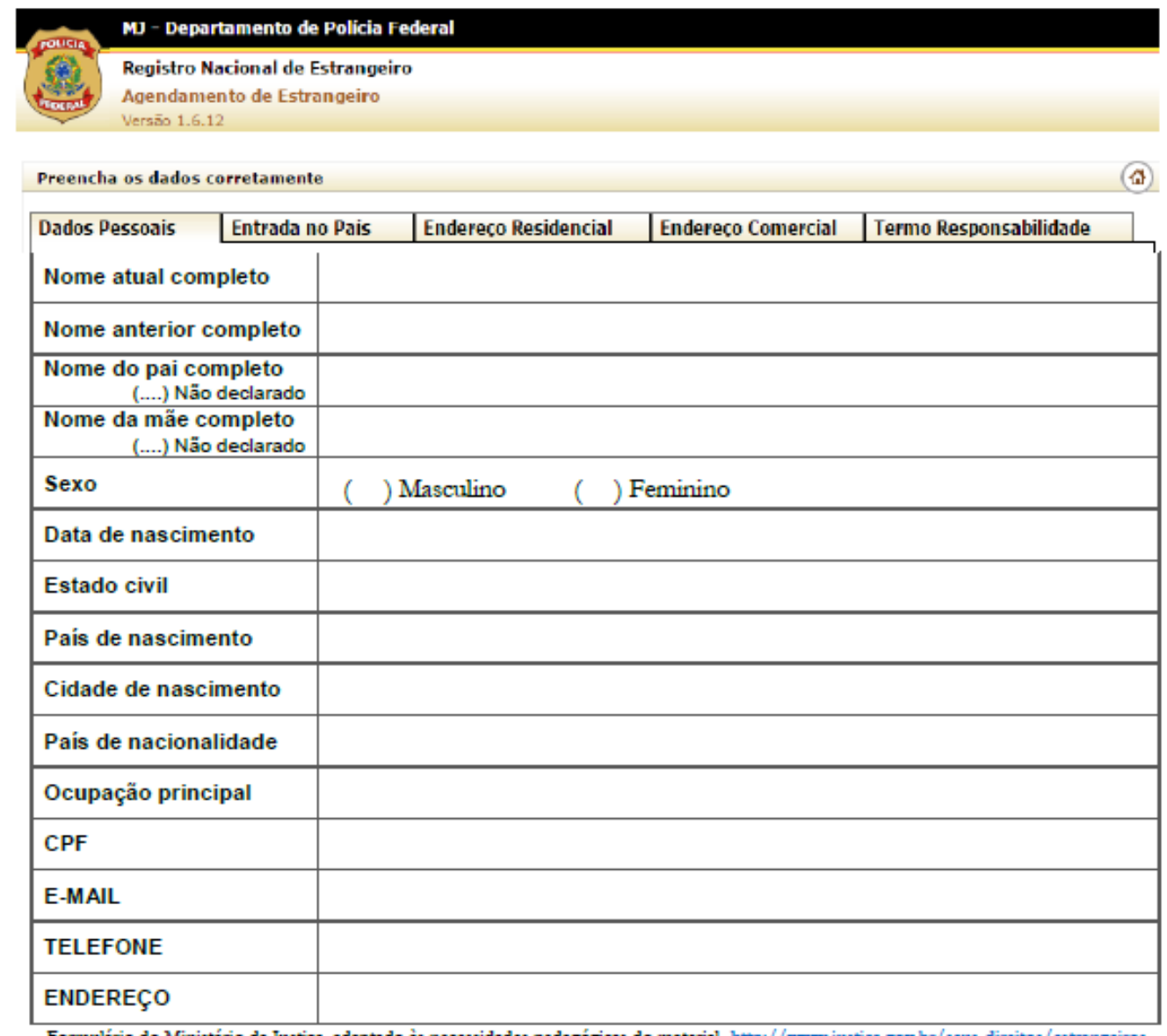

FIGURA 1 - Pode Entrar: Português do Brasil para Refugiadas e Refugiados FONTE: AMARO et al. $(2015$, p. 16).

Nesse sentido, buscamos desenvolver uma atividade menos controlada, com menor exigência de adequação a um modelo prévio, em que o discurso do aluno pudesse assumir formas e conteúdos mais livres. Nas seis entrevistas assistidas e analisadas ao longo das atividades que antecedem a produção escrita, cada brasileiro que se apresenta possui seu próprio estilo e seu modo de materializar, de dar tom,ao discurso. Em perspectiva similar, esta experiência se concentrou menos na tentativa de aproximar o migrante de um suposto modelo de "falante nativo", e mais nas aptidões linguísticas que os alunos

7 Publicada em 2015 pelo Alto Comissariado das Nações Unidas para Refugiados (ACNUR) em parceria com o Curso Popular Mafalda e a Cáritas Arquidiocesana de São Paulo (CASP). 
podem desenvolver, na medida em que encontram, exploram e se apropriam dos recursos necessários para expressarem seus próprios conteúdos.

A partir dos enunciados, procuramos compreender como estes alunos falam sobre si, que temas abordam, que significados perpassam suas apresentações. $\mathrm{Na}$ análise dos discursos, para além de verificar as formas de uso da ferramenta língua portuguesa, partimos do pressuposto de que os discursos são diálogicos, ou seja, contruídos no âmbito das relações com o contexto presente e também fruto de uma perspectiva histórica, cultural e social (BAKHTIN, 1998). Nessa perspectiva, toda a experiência de vida do migrante é o que o singulariza, portanto, o olhar para os sentidos individuais daquilo que os alunos enunciam faz perceber as nuances dos discursos, que são justamente o conteúdo das nossas reflexões sobre as identidades destas populações, em oposição ao sentido unívoco que comumente define a categoria migrante-refugiado.

Zarate et al. (2008, p. 149) apontam para este movimento de categorização do migrante, no sentido de que os discursos da vida cotidiana, da mídia, das instituições acabam simplificando o grande número de indivíduos reais a uma categoria como, comunidade síria, comunidade haitiana, que não leva em consideração a diversidade das situações e de trajetórias de vida de cada pessoa. Ainda, de acordo com os mesmos autores, uma observação cuidadosa das realidades migratórias continua revelando as diferenças entre as atribuições etno-nacionais e a multiplicidade de estratégias que os recém-chegados desenvolvem para redefinirse e negociar um espaço social na sociedade de acolhimento ${ }^{8}$.

Com base nessa perspectiva de análise, as onze produções escritas realizadas em sala de 8 Tradução nossa. Texto original: "Une observation attentive des réalités migratoires ne cesse de révéler des écarts entre les attributions ethno-nationales et la multiplicité de sstratégies que les nouveaux arrivants développent pour se redéfinir et négocier unespace social dans la société d'accueil”. aula, durante aplicação da UT, foram transcritas ${ }^{9}$ ipsis litterisa fim de preservar a integridade dos discursos, ou seja, os sentidos unívocos dos enunciados, que se relacionam à expressão individual de cada sujeito. Excertos das produções escritas serão pontualmente apresentados sob a forma de enunciados isolados (e neste caso, estarão contextualizados) a fim de discutir as possibilidades de sentidos provenientes do tema proposto a apresentação pessoal. Tendo esclarecido os critérios metodológicos que fundamentam a análise dos discursos, apresentamos a seguir as produções escritas, para em seguida discutir sobre os sentidos que emanam dos enunciados dos alunos.

Aluno 1 - Produção escrita (Básico 1A/PBMIH)

Ola

Meu nome é Aluno 1

Eu sou haitiano

Eu sou pedeiro

Eu tenho trenta e seis anos

Eu não casado

Eu moro no cachoiera

Eu tenho sete mesis Brazil

Eu gosto joga bola

Eu vou na igreja uma dia pro semana

Aluna 2 - Produção escrita (Básico 1A/PBMIH) Oi toudou bom meu nome é Aluna 2

Eu tenho 27 anos Eu sou haitiana profissão é

Cozinhar estou trabalha empresa

eu casada tem dois criança um filho

uma filha eu moro no Brasil em Curitiba

todou familia haiti só problema eu tem

eu saudade familia. Só is tà bom tchau.

Aluno 3 - Produção escrita (Básico 1A/PBMIH)

Meu é Aluno 3

eu sou haitiano

eu sou pedeiro

eu sou casado

eu tenho 41 anos

$9 \mathrm{Na}$ transcrição os nomes alunos foram substituídos por Aluno 1, 2 3, e os nomes dos familhares por Filho(a), Pai, Mãe, etc., a fim de preservar o anonimato. Nas análises, fazemos a referência do seguinte modo: Aluno 1 - A1, Aluno $2-\mathrm{A} 2$, etc. 
eu moro no Brazil

eu tenho 3 filho

eu gosto curse do português

Aluno 4 - Produção escrita (Básico 1A/PBMIH)

Meu nome é Aluna 4

e sou haitiana e sou estudante

Moro no brasil

Tenho 27 anos de idade

e não sou casada

e tenho um filho

Aluno 5 - Produção escrita (Básico 1A/PBMIH)

Sou Aluno 5

Sou Haitiano

Sou soldade electríca

MORO brasil pinahis parana

Sou casado

Sou 40 anos.

Sou 2 anos brasil

No trabalhas

Sou bouscado trabalhao

POR ajouda Aluga Casa

Aluna 6 - Produção escrita (Básico 1A/PBMIH)

eu sou Aluna 6, eu tenho 23 anos

eu sou haitiana, meu professão: Faxineira

moro em Brasil Cidade Curitiba

sou casada tenho um filho

e depois eu gosto de dança e musica

eu gosto tambem de jogo de baskett ball

Aluno 7 - Produção escrita (Básico 1A/PBMIH)

eu nome é Aluno 7 eu tenho 18 anos eu sou Sireo

eu moro no Brasil em curitiba meu musica

favorito é engles meu cantora favorito está

wanassa eu falo arabe, englês e agura estudando

portugués eu gosto comidas arabe e em sonhos

futuros quero ajudar pessoas que não falam portugués

eu tambem quero estudar em universidade

e eu sou solteiro

Aluna8 - Produção escrita (Básico 1A/PBMIH)

Eu sou Aluna 8, Sou haitiana

Eu tenho 36 anos eu casada eu moro no brasil

Curitiba eu sou farmaceutica eu não trabalha

No brasil eu tem uma filha Ela se chama Filha

ela muito bonita. Eu gosto

a musica minha filha gosto jugo fotbol o televisão

Aluna 9 - Produção escrita (Básico 1A/PBMIH)

meu nomie Aluna 9

Eu moro no Brasil em curitiba

Eu tenho 53 anos

Eu sou sirya

Eu não sou casado, sou divorciado

Eu gosto vivo em Brasil sempre

Aluna 10 - Produção escrita (Básico 1A/PBMIH)

My nome é Maram, sou síria, moro no Brasil

em Curitiba no centro, tenho vinte e quatro

anos de idade, sou farmacêutica, Agora

não trabalho, estudei farmacia na universidade

de Damascu. Eu cheguei ao Brasil há

dois meses. Sou casado, meu marido

se chama Marido, ele sou sirio também

, ele morou no Brasil há trez anos. Ele

me ajuda aprender língua aqui. Eu

quer trabalhar ou fazer mestra no

químico farmacêutica aqui no Brasil.

Aluna 11 - Produção escrita (Básico 1A/PBMIH)

Meu é Aluna 11. Eu tenho 26 anos. Eu sou

Haitiana. Eu ainda não profissão. Eu moro no

Brasil em Curitiba. Eu sou solteiro. Para outras

Informações eu quero estudar em Brasil trabalhar

Tembém, eu quero falar portugues muito bem, para o

Fazer meu todo actividade em Brasil, Eu gosto cantor

Eu moro com meu tio, eu sou crente. Eu gosto a cotabilidade

E a medicina tembém. Eu tenho muitos paravras...

Muito obrigada...

Depreende-se dos enunciados a percepção de que há, de fato, uma vontade de inserção no mercado de trabalho e no meio acadêmico, como nos seguintes enunciados: A5 "No trabalhas [...] Sou bouscado trabalho", A7 "eu tambem quero estudar em universidade", A10 "Eu quer trabalhar ou fazer mestra no químico farmacêutica aqui no Brasil”, A11 "Eu ainda não profissão [...] eu quero estudar em Brasil trabalhar". Ainda, a necessidade de acesso à moradia aparece em: A5 "POR ajouda Aluga Casa". Desse modo, temas diretamente relacionados ao acesso à cidadania afloram nos 
enunciados, o que reitera nossa reflexão inicial sobre o desafio vivido por estas populações, que de um lado têm o visto humanitário que dá o direito de permanência no país e de outro lado têm dificuldade de inserção efetiva nestes espaços.

Para além das preocupações com a sobrevivência no país, encontramos também os discursos que remetem aos sentidos do micromundo destes alunos - que falam das atividades quotidianas, das preferências de entretenimento e lazer e das relações com a família: A1 "Eu gosto joga bola Eu vou na igreja uma dia pro semana"10, A6 "eu gosto de dança e musica eu gosto tambem de jogo de baskett ball" e A8 "Eu gosto a musica minha filha gosto jugo fotbol o televisão". A percepção do que podemos chamar de gostos pessoais está associada aos esportes, como futebol, basquete, às atividades culturais, como música e dança e à televisão. No enunciado A2 "todou familia haiti só problema eu tem eu saudade familia", não é possível saber se os conflitosrelacionais engendraram ou não rompimento de contatofamiliar. Contudo, é possível perceber que o vínculo afetivo continua existindo e é associado ao termo "saudade". Interessante notar que o aluno se apropriou de uma palavra própria do português brasileiro para expressar-se nesse sentido.

Finalmente, se o aprendizado do $\mathrm{PB}$ não é necessariamente uma escolha voluntária dos alunos, observamos, contudo, uma relação afetiva com o processo de ensino-aprendizado da língua em A3 "eu gosto curse do português" e sentidos que remetem a um tipo deassistência no processo de ensino-aprendizado da língua: A7 “em sonhos futuros quero ajudar pessoas que não falam portugués" e A10 "meu marido se chama Marido, ele sou sirio também, ele morou no Brasil há trez anos.

10 Neste caso, não pretendemos entrar no mérito do exercício da fé, da crença ou da religiosidade; o significado que depreendemos deste enunciado remete ao sentido de uma atividade social por ele valorizada no quotidiano.
Ele me ajuda aprender língua aqui”. Nesse sentido, somente em A11 "eu quero falar portugues muito bem, para o Fazer meu todo actividade em Brasil", percebemos a relação - falar português muito bem para fazer toda a atividade no Brasil, que remete à ideia de que o domínio da língua nacional seria como uma chavede acesso para as demais atividades sociais. Interessante perceber como ela concluí sua fala: A11 "Eu tenho muitos paravras...", como se quisesse mostrar o potencial de abrangência do seu discurso, que por outro lado prossegue silenciado através das reticências.

\section{Considerações finais}

Em conclusão, a partir da análise das produções escritas, reiteramos a importância da existência de espaços sociais que possam dar vOZ aos alunos, proporcionando-lhes um lugar de fala que contribua para a desconstrução da imagem homogeneizante comumente baseada em uma generalização, que cria uma concepção abstrata de identidade - através do rótulo migrante, refugiado. Se este rótulo tende ao apagamento das individualidades, tais experiências pedagógicas podem funcionar como ações de desconstrução e de resistência, evocando aqui os termos usado por Zarate et al. (2008), no sentido de contribuir para o processo de empoderamento identitário do migrante, em sua busca por existir neste lugar de outra língua, outra cultura.

Nesse sentido, através da análise dos discursos, nos deslocamos desta imagem estereotipada do migrante para uma outra imagem - a da mãe de família que tem uma filha bonita, do estudante sírio que está estudando português, do cidadão que está procurando trabalho e casa para alugar, em resumo, do indivíduo singular - que se define a partir das próprias palavras, escolhendo qual imagem quer construir sobre si. Para Zarate et al., 
Essas redefinições identitárias e estratégias de resistência às categorizações visam precisamente a construção de uma autoimagem, baseada em identidades mais significativas para os indivíduos, que expressa uma luta contra uma grande visibilidade cultural e seu oposto. Elas também permitem aos migrantes arranjar espaços de integração social parcial. ${ }^{11}$ (ZARATE et al., 2008, p. 151-152)

Nessa perspectiva, o objetivo desta experiênciafoi também criar estratégias de ensino que levassem os alunos a ressignificar a própria relação com a língua, geralmente percebida por eles como um empecilho para a inserção social (ANUNCIAÇÃO, 2017, p. 95). Nossa intenção foiusar o espaço da universidade pública e consequentemente, da sala de aula, para criar um ambiente enunciativo onde os migrantes pudessem materializar, através do discurso, na apresentação pessoal, os seus próprios conteúdos identitários e assim, usar a língua portuguesa não como entrave da expressão de si, mas sim, como recurso. Nesse sentido, a pesquisa de Anunciação (2017) já havia constatado que o PB não representa somente um impedimento para a inserção social, existem outros espaços onde ele é usado como recurso, na medida em que serve para que os migrantes desenvolvam estratégias de expressão de si mesmos.

Além da relação com a língua nacional, o fenômeno migratório é em si, uma realidade que faz constatar que os espaços de interação socioverbal estão cada vez mais fluídos e plurais. Os migrantes que vêm de países africanos falam inglês, francês, árabe, além de suas línguas regionais. Sírios e libaneses falam as variedades de Árabe e Inglês. Haitianos geralmente falam Francês e Crioulo, Haitiano; mas muitos deles acabam também aprendendo o espanhol, pois acabam passando por outros países da América Latina antes de chegarem 11 Tradução nossa. Texto original: "Ces redéfinitions identitaires et ces stratégies de résistance aux catégorisations nationales visent précisément à construire une image de soi, fondée sur des identités plus signifiantes pour les individus, qui exprime une lutte contre une trop grande visibilité culturelle et son contraire. Elles permettent aussi aux migrants d'aménager des espaces d'intégration sociale partielle". ao Brasil. Em resumo, o plurilinguismo é a realidade do atual contexto migratório, independente do modo como a receberemos no espaço escolar.

A nosso ver, o perfil plurilingue e pluricultural dos migrantes e refugiados é uma realidade que deve ser assimilada pelas práticas pedagógicas, e não desconsiderada. O campo de estudos da didática e das metodologias de ensino está em constante mudança justamente por conta dos fatores sociais, políticos e econômicos, os reais impulsionadores das transformações. Além disso, as inúmeras tensões do movimento migratório, como as expectativas individuais, a autoestima, os planos para o futuro, a busca por trabalho, o distanciamento dos familiares e o modo como o lado do acolhimento reage a este contexto são condições próprias do refúgio, que afetam diretamente no aprendizado da língua nacional.

Em suma, todo este contexto linguístico e extra-linguístico deve ser considerado no ensino do PB como língua de acolhimento. Nesse sentido, o desafio de projetos como o PBMIH é apreender tal complexidade para criar ações eficazes de acolhimento da população migrante. $O$ olhar investigativo para as nuances e singularidades deste público não significa a recusa de uma compreensão mais ampla de suas dinâmicas, que podem resultar em respostas norteadoras tanto para a prática docente, quanto para a estruturação decursos e para o desenvolvimento de políticas;na realidade, um eixo está interligado e influencia o outro.

Por fim, além de buscar contribuir para a formação linguística e cultural das populações migrantes no aprendizado do $\mathrm{PB}$, a expectativa é que os resultados da pesquisa mais ampla se convertam em subsídios para a integração da IC enquanto recurso para o ensino-aprendizado do PB em contexto migratório e, consequentemente, colaborem com as demais ações de acolhimento, como o planejamento de cursos de PLAc, a formação docente na área, as políticas linguísticas 
no ensino superior e fora dele, entre outras.

Ainda, esperamos que os resultados contribuam para o debate científico, em uma perspectiva que ultrapasse o caráter meramente empírico, mas que enriqueça a discussão teórica da área estudos na qual a pesquisa está situada.

\section{REFERÊNCIAS BIBLIOGRÁFICAS}

CANDELIER, M. (coord.), Camilleri-Grima, A., Schröder-Sura, A. \&Noguerol, A. CARAP - Cadre de Référence pour les Approches Plurielles des Langues et des Cultures. Conseil de l'Europe/ CELV, 2007.

CONSEIL DE L'EUROPE. Cadre européen commun de référence pour les langues :apprendre, enseigner, évaluer -volume complémentaire avec de nouveaux descripteurs. Paris: Les Editions Didier, 2018.
AMARO, T.; FASSON, K.; FEITOSA, J.; MARRA, J.; MOREIRA, N.; PEREIRA, R. Pode Entrar: Português do Brasil para refugiadas e refugiados. São Paulo: ACNUR, Cáritas, Curso Popular Mafalda, 2015.

ANDRADE, A. I.; MARTINS, F. Em torno do conceito de intercompreensão: desafios e possibilidades na formação pós-graduada de professores. In: MORDENTE, O. (Org.). Novas tendências no ensino/aprendizagem de línguas românicas e na formação de professores. São Paulo: Humanitas, 2015.

ANUNCIAÇÃO, R. F. M. Somos mais que isso: práticas de (re)existência de migrantes e refugiados frente à despossessão e ao não reconhecimento. Dissertação Mestrado Campinas, SP: 2017.

BAKHTIN, M. M. Os gêneros do discurso. In: Estética da criação verbal. Tradução de: PEREIRA, M. E. G. São Paulo: Martins Fontes, 1992.

BAKHTIN, M. M. O discurso no romance. In: Questões de Literatura e de Estética. Teoria do Romance. São Paulo: Hucitec, 1998.

BAKHTIN, M. VOLOCHINOV, V. N. Marxismo e Filosofia da Linguagem. São Paulo: Hucitec, 2009.

CABETE, M. A. O processo de ensinoaprendizagem do português enquanto língua de acolhimento. Dissertação de Mestrado. Universidade de Lisboa, Lisboa, 2010.
ESCUDÉ, P. ; JANIN, P. Le point sur l'intercompréhension, clé du plurilinguisme, coll. «Didactique des langues », CLE International, Paris, 2010.

GROSSO, M. J. dos Reis. Língua de acolhimento, língua de integração. Horizontes de Linguística Aplicada, v. 9, n. 2, 2010, p. 61-77.

PALMERINI, M.; FAONE，S. No caminho em direção à intercompreensão. Umareflexãoepistemológica. Revista X, v. 2, 2014.

SHEEREN, H. L'intercompréhension: un nouveau souffle pour les langues romanes minoritaires et pour les dialectes ? Lengas [En ligne], 79 | 2016.

VAILATTI, T. F.; OLMO, F. J. C. A intercompreensão como ferramenta didática para o ensino do português brasileiro no PBMIH. Letra Magna (Online)., v.23, 2018, p. 2438.

ZARATE, G.; LEVY, D.; KRAMSCH, C. Précis du plurilinguisme et du pluriculturalisme. Editions des archives contemporaines, 2008.

Submissão: outubro de 2019. Aceite: março de 2020 